Przemysław Adam Wiśniewski, La discendenza di Aronne. Studio diacronico di Ex 24*; Lv 10*; Nm 17*; Nm 27* (Supplementi alla Rivista Biblica 62; Bologna: Edizioni Dehoniane Bologna 2017). Pp. 282. € 36,00. ISBN 978-88-10-254-5

\title{
BARBARA RZEPKA
}

Monastero della SS. Trinità, Poppi (AR), Italy

barbarabasamon@yahoo.it, ORCID: 0000-0003-0813-0195

The book we are presenting is the doctoral thesis of Przemysław Adam Wiśniewski, written during his studies at the Pontifical Biblical Institute in Rome, under the guidance of Professor Jean-Louis Ska. The author devotes his research to an intriguing as well as very complex story concerning the descent of Aaron. His study appears as a real investigation into the sudden and mysterious death of Aaron's two eldest sons, Nadab and Abihu (Lv 10:1-3), and into the meteoric career of the third son Eleazar who reached the leading position of High Priest (Nm 17:1-5). The author analyzes four texts: Ex 24*; Lv 10*; Nm 17*; Nm 27*, which tell the story of the first descendants of Aaron. The purpose of the research is not limited solely to the exegetical study of the texts. This study, in fact, aims to find the historical background of the facts referred to in the analyzed passages and to discover what people were actually responsible for the events that led to the designation of Eleazar as the high priest. The book consists of five chapters, the first four of which are dedicated to the diachronic study of the four passages indicated above. In the analysis of each passage, Wiśniewski applies the historical-critical method. He therefore deals with the delimitation of the text, solves the open issues concerning translation, textual criticism and literary problems, and finally analyses the meaning of the specific given passage, its purpose, dating and historical background. Sometimes the author also supports his research with the use of narrative analysis. The fifth and final chapter is dedicated exclusively to the issues concerning the dating and the historical background of Nm 17:1-5 and Nm 27:12-23.

The first chapter, entitled "The great privilege of the sons of Aaron," focuses on the analysis of Ex 24:1a.9-11. The objective pursued with the analysis of the story is to discover the aim of the text and its relationship with the history of Israel. Different scholars analyze various hypotheses regarding the purpose of this pericope. Among these hypotheses Wiśniewski chooses to deepen the one nearer to the aim of his research: the visio Dei and the banquet in the presence of YHWH legitimate 


\section{BARBARA RZEPKA}

those who receive the authority and the related responsibility. The analysis shows that both elements represent the same reality, that is, the privilege granted only to God's elect, a privilege that confirms their mission. Therefore, the research focuses on the "privileged," that is, on the historical-social identity of the elders and of Nadab and Abihu, as we find in Ex 24:1a.9-11. Some prophetic texts (Ez 8 and Jer 26) suggest that the expression "seventy elders" is to be associated with a specific group of people in charge in Israel, seeking for their social position in the new reality following the exile to Babylon. On the other hand, on the basis of the priestly tradition texts (Ex 28:1), the author identifies Nadab and Abihu as the two eldest sons of Aaron. It was shown that the text is not attributable to any of the sources of the Pentateuch. Wiśniewski analyzes the vocabulary to define the dating of the text and sees that it is late, i.e. a post-exilic vocabulary. This analysis makes it possible to ascribe the text to a post-P editor, dated to the late Persian era. The comparison of the above passage with Ezra 1-6, along with a careful linguistic and historical analysis, leads the author to the conclusion that both texts have the purpose of legitimizing the elders and the priests in view of their common endeavour of handling the new post-exile social situation. The chapter ends with an interesting Excursus on the investiture of the elderly, in Nm 11:16-17.24-25. This text, in addition to Ex 24:1a.9-11, is the only one that deals with the legitimacy of the institution of the seventy elders, rooted in the Mosaic tradition.

The second chapter, entitled "The death of the sons of Aaron," is devoted to the study of the short and very cryptic story narrated in Lv 10:1-3. Wiśniewski provides an overview of the solutions to the enigma of the death of Nadab and Abihu, presented by commentators throughout the history of exegesis, including divine judgment, cultic error, moral or religious fault, violation of cultic norms, use of illegitimate incense or of profane fire, apostasy of the two offerers of incense, an action which was not commanded or was reserved only to the high priest, etc. Since none of the explanations of the death of Nadab and Abihu proposed by the ancient, medieval or modern authors leads to a definitive solution accepted by the majority of scholars, Wiśniewski brings forward his own proposal, a very interesting and original one, that requires a change of the exegetical perspective. In fact, he proposes to abandon the moral perspective and to analyze the event with "the lenses of an ancient writer," offering a theocentric interpretation. The analysis shows that the purpose of the passage is of a political-religious type, namely it concerns the conflict between two priestly groups (the descendants of Nadab and Abihu, on the one hand, and the descendants of Eleazar, on the other) and seeks to justify the divine election of Eleazar as the high priest. To do so, the editor tells the story of the tragic death of Nadab and Abihu attributing it to the divine will. According to the study of the biblical tradition concerning the death of the two brothers (Lv 16:1; Nm 3:1-4; 26:60-61, 1 Chr 24:1-2), we can attribute Lv 10:1-3 to a post-P editor, living approximately in the third or second century BC, during the final phase of the composition of Leviticus. In order 
to define the background of the pericope the author goes through the history of priesthood in Israel, from the pre-monarchical era to the post-exile period, during which there are other episodes similar to the one narrated by Lv 10:1-3. From these analyses we understand the historical context of the pericope, in which a priestly group in the Hellenistic era traces its genealogy from the third son of Aaron, Eleazar, in an attempt to reach the high priesthood. Using a frequent biblical motif, namely bringing the eldest son into discredit to facilitate the ascent of a younger brother, this priestly group eliminates from the stage of history Nadab and Abihu, to establish the right to the high priesthood exclusively to Eleazar's descendants.

The third chapter is entitled "Eleazar towards the high priesthood" and concerns the study of Nm 17:1-5, which reveals the mysteries of Eleazar's career advancements, from third son to "firstborn" of Aaron and from a simple priest to the high priest. The lexical and stylistic analysis and the content of the pericope prove the post- $\mathrm{D}$ and post-P editorial origin, corresponding to the final phase of the redaction of the Pentateuch. An interesting element of this chapter of the study is how the stylistic analysis shows the editor's attempt to imitate the style of the priestly author $(\mathrm{P})$. Wiśniewski enriches his research proving the presence of the same scribal activity in Nm 15:37-41, where to the oldest texts is given a new meaning. According to the author, the presence of "Eleazar instead of Aaron, as being next to Moses, anticipates the events of Nm 20 and outlines the figure of the successor to the major priestly office" (p. 148). The historical background envisions the juridical conflict between Moses and Aaron, on the one hand, and 250 men of Korah, on the other hand, as well as the divine sentence that decrees Eleazar as the victor, having the censers as a memorial sign of this victory. It should be noted that the victory is attributed to Eleazar and not to Aaron, in order to legitimize Eleazar's descendants in the service of the high priest, and to keep this binding also after Aaron's death.

The fourth chapter, entitled "Commands of Eleazar and Joshua's investiture," deals with the story narrated in Nm 27:12-23, which is the last passage examined in Wiśniewski's study. The close examination of the delimitation of the text and the textual analysis of the passage revealed some tensions in the story, from a literary point of view, that can be solved through the study of ancient translations. The homogeneity of the text is proven by comparing it with $\mathrm{Dt} 32: 48-52$, which is recognized as the basic text for Nm 27:12-13. The examination of the formal and content aspects leads Wiśniewski to discover a deep affinity between the two pericopes, to the point of recognizing the hand of the same author. The stylistic and linguistic study, which reveals the use of a late vocabulary throughout the passage, enabled Wiśniewski to conclude that Nm 27:12-23 is a unitary text. Unlike the scholars who divide Nm 27:12-23 into two parts (vv. 12-14 and 15-23), Wiśniewski's research is not limited to the comparison of the passage with Dt 32:48-52, but, instead, conducts a more complex investigation that takes into account the affinities between $\mathrm{Nm}$ 23:12-14 and 15-23. On the basis of these analyses, the research shows that there are no plausible reasons to di- 
vide the story into two parts. The examination of the style, vocabulary and content highlights the similarity of the passage with $\mathrm{Nm}$ 17:1-5. Moreover, the pre-existing material (Ex 38:2 and Dt) is reinterpreted to convey a new message regarding the important role of Eleazar. The "clumsy" style of the stories reveals the tendency to imitate the priestly author $(\mathrm{P})$. The contextual changes reveal the late provenance of $\mathrm{Nm}$ 27:12-23 (post-P and post-D) and indicate the hand of the same editor as in $\mathrm{Nm}$ 17:1-5. Then the study focuses on understanding the purpose of the passage. The proposals of various commentators are analysed, which differ according to the various interpretations they give to the relationship between Joshua and Eleazar and their roles. It seems that the model present in the first generation, in which the charismatic leader (Moses) was accompanied by the priest (Aaron, Eleazar), no longer works in the second generation. Therefore, there is a reversal of roles and the story of Nm 27:12-23 justifies this new order, irrevocably established by God, in which the charismatic leader (Joshua) becomes subject to the priest (Eleazar). Furthermore, in this new disposition, the high priest not only has supremacy, but also expands his power from the religious to the socio-political sphere.

Wiśniewski dedicates the fifth and final chapter to the "Historical dating and background of Nm 17:1-5 and Nm 27:12-23". Wiśniewski decides to investigate the dating and the historical background of these two stories together, because of the numerous common elements between the two passages and of their late provenance, and because they have the same editor. First of all, the author examines the texts that mention Eleazar as the only successor of Aaron and then goes on to analyze the passages that confirm Eleazar's supremacy over Joshua. The figure of Eleazar appears only in post-exilic texts and his person is particularly important in the work of Chronicler. From the study of the texts belonging to the biblical tradition on the succession of Eleazar, above all the genealogies in 1-2 Chr, the list of ancestors in Ezra 7:1-5 and the Book of Joshua, it emerges clearly that $\mathrm{Nm}$ 17:1-5 and Nm 27:12-23 are late texts and probably date to the Hellenistic period of the third century BC, i.e. the period in which there is a particular interest in the figure of Eleazar. Then the author moves on to study the background of the two passages, starting from the analysis of the priesthood in the third century BC in the province of Yehud at the time of the Ptolemaic rule. The lack of biblical and extra-biblical historically valid documents on the high priesthood in Jerusalem objectively limits the research and gives, in principle, only a level of plausibility to its outcome. According to the known sources, from the end of the fourth century $\mathrm{BC}$ to $175 \mathrm{BC}$, the position of high priesthood was held by members of the Oniad family, and the first to hold that office was Onias. Wiśniewski investigates the identity of the Oniads, handling very well the exegetical tools, and on the basis of the available literary, historical and archaeological material, he concludes that the historical circumstance concomitant with the composition of Nm 17:1-5 could be the rise of Onias, after the high priest Hezekiah's deportation to Egypt. This literary production could, in fact, allow the Oniads to document their direct 
descent from Eleazar and to present themselves as the only continuers of the ancient priestly traditions. Numbers 27:12-23 was instead aimed at justifying the socio-political ambitions of the Oniads in the administration of the Judea region, against the limiting policy of the Ptolemaic rulers and the growing economic and administrative influence of the landowners, such as that of the Tobiads in the first half of the third century BC.

In the conclusion of the book, the author exposes some methodological premises of his study, including the exegetical research into the historical background of

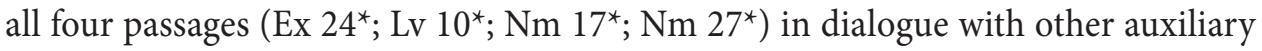
fields of study. Furthermore, Wiśniewski lists the "novelties" that his research brings into the research on the priesthood of the Aaronites, a topic little explored so far. This novelty includes the juxtaposition of biblical texts, often studied separately, and the analysis of their mutual connections, regarding also their origin and chronological sequence, given that all these texts are late, post-D and post-P. At the end of his investigation, Wiśniewski attributes the examined passages to two distinct authors or editors. The first, from the Persian period, composed Ex 24:1a.9-11 in order to legitimize the role of the elders and the priests in the post-exilic society and to indicate Nadab and Abihu as the representatives of the high priesthood. Then Wiśniewski attributes the following passages to a second author: Lv 10:1-3, Nm 17:1-5 and 27:12-23. Their composition can be placed at the time of the ambitious Oniad priestly family in the Hellenistic period. The biblical author sets aside Nadab and Abihu ( $\operatorname{Lv}$ 10:1-3), using the weapon of discredit, so as to make room for the promotion of Eleazar and his descendants to the office of the high priest (Nm 17:1-5) and their consequent supremacy (Nm 27:12-23). In fact, the texts produced by this second author allow the Oniad family to trace the roots of their role as high priests directly to the person of Eleazar. The volume ends with an extensive bibliography, indexes of authors, biblical and extra-biblical citations, and a general index.

Wiśniewski has undertaken the difficult task of unveiling the secrets of the history of the first descendants of Aaron and managed to unravel the long-standing issue of Eleazar's rise to the role of supreme leader of Israel, detecting the "culprits" of the elimination of Nadab and Abihu with their descendants from the stage of the dramatic priestly history in Israel. The author carries out his investigation in an interdisciplinary way through the dialogue between biblical exegesis, archeology, history and ancient literature. He selects the material critically and evaluates the information to find some useful clues for the reconstruction of the historical-cultural background of the passages, paying attention to all details. Moreover, the author resists the temptation of trying to say everything and to consider some secondary, non-essential issues. He always manages to focus on the goal of his study, thus maintaining linearity, compactness, and clarity in the development of his thought. By conducting detailed analysis on particular issues, he never loses sight of the global vision of his research. Thanks to the frequent summaries of his exegetical procedures, he helps the reader to 
easily follow his thought, eventually boosting the reader's interest in the topic. In our opinion, the careful study conducted by Wiśniewski produced some excellent conclusions regarding Aaron's descent. His original conclusions are not only very useful, but also indispensable, in any further research on this topic. The value of his study lies not only in the results obtained, but also in the creative way in which the research was conducted. This learned study represents an important contribution to the better understanding of the turbulent history of priesthood in Israel. 